\title{
TROMBOFILIAS HEREDITÁRIAS
}

\author{
INHERITED THROMBOPHILIAS
}

Rendrik F. Franco

Professor Livre-Docente de Hematologia e Hemoterapia. Coordenador do Serviço de Investigação em Hemofilia e Trombofilia, Fundação Hemocentro de Ribeirão Preto. Coordenador do Laboratório de Hemostasia, Hospital das Clínicas da Faculdade de Medicina de Ribeirão Preto, Universidade de São Paulo

CorrespondênCIA: FUNDHERP, Rua Tenente Catão Roxo, 2501 - 14051-140, Ribeirão Preto, SP. E-mail:_rendri@hotmail.com

FRANCO RF. Trombofilias hereditárias. Medicina, Ribeirão Preto, 34: 248-257, jul./dez.2001.

RESUMO: Na presente revisão, discutimos a contribuição de fatores genéticos para a ocorrência de tromboembolismo venoso.

UNITERMOS: Trombose. Gene. Fatores de Risco.

\section{INTRODUÇÃ̃}

Em contraste com as doenças monogênicas, em que mutações em um único gene resultam em doença, no caso de doenças multigênicas, diferentes mutações em genes distintos interagem para ocasionar a doença. Neste caso, o risco de manifestação da doença, associado a cada alteração genética, isoladamente, é relativamente baixo, mas a presença simultânea de mutações em genes diversos culmina na sua ocorrência. As doenças multigênicas podem também ser compreendidas como conseqüência da interação de coleção heterogênea de elementos de natureza genética com eventos ambientais: além de multigênicas são, portanto, usualmente, multifatoriais, ou resultantes da superposição de mecanismos fisiopatológicos de natureza hereditária e adquirida.

O conceito de doença multigênica é aplicável a numerosas condições clínicas e de fato inclui uma vasta gama de entidades tais como câncer, hipertensão, diabete melito, dislipidemias, obesidade, susceptibilidade a infecções, doenças auto-imunes, osteoporose, aterosclerose e tromboembolismo venoso (TEV). $\mathrm{O}$ controle genético da susceptibilidade a cada uma dessas condições é multigênico. Dentre os exemplos, o TEV foi, provavelmente, a doença sobre a qual o maior número de informações foram acumuladas recentemente, acerca da contribuição de fatores hereditários, determinando a ocorrência de uma doença poligênica. Por tal razão, no presente capítulo, o TEV será discutido como paradigma das doença multigênicas. Os conceitos gerais, apresentados a seguir, podem ser compreendidos, portanto, como o exemplo clássico de influência multigênica, influenciando a ocorrência de uma doença.

\section{TROMBOEMBOLISMO VENOSO COMO PROTÓTIPO DE DOENÇA MULTIGÊNICA}

Ao longo do século XX, surgiram as primeiras descrições de famílias com predisposição aumentada para apresentar eventos trombóticos (em especial trombose e embolia pulmonar após operações e gravidez $)^{(1)}$. Obviamente, o conhecimento limitado acerca da composição química do sangue e das propriedades dos sistemas que regulam a formação do coágulo de fibrina, assim como a disponibilidade reduzida de recursos diagnósticos de eventos trombóticos, limitaram investiga- 
ções mais aprofundadas dessas condições naquela época. Entretanto, é interessante notar que, já nos relatos da época, podem ser identificados os elementos que compõem a visão mais atualizada que temos acerca da entidade clínica, a trombose venosa: o de que fatores de risco circunstanciais (por exemplo, operações, ou gravidez) contribuem para a ocorrência do evento trombótico, mas que fatores genéticos (cuja existência poderia ser presumida pela tendência familiar à trombose) coexistem e também determinam o risco de trombose.

Nas últimas décadas, progressos substanciais ocorreram na compreensão de mecanismos fisiopatológicos, operantes no TEV. Um conjunto de anormalidades, associadas à hiperatividade do sistema da coagulação do sangue e/ou ocorrência de fenômenos trombóticos, foi reconhecido, e a descrição dos estados de "hipercoagulabilidade" modificou nossa visão acerca do TEV. Em particular, foi assimilado o conceito de que alterações genéticas, que resultam em hipercoagulabilidade são identificadas em grande número de pacientes com doença trombótica venosa. Tal conceito resultou, ainda, na introdução do termo trombofilia para definir uma predisposição aumentada, usualmente genética, para a ocorrência de $\operatorname{TEV}^{(2,3)}$.

A patogênese do TEV ainda não se encontra completamente elucidada, mas há evidências claras de que o processo é influenciado pela complexa interação de fatores genéticos e ambientais, que receberam a denominação genérica de fatores de risco. A caracterização de fatores de risco para TEV representa etapa fundamental para a compreensão da patogênese dessa entidade clínica. Vale ressaltar que os fatores de risco para doença trombótica venosa (TEV) diferem dos fatores de risco para doença trombótica arterial (hipertensão arterial, tabagismo, dislipidemia e diabetes, por exemplo, não são associados a risco aumentado para TEV). Fatores de risco, adquiridos, clássicos para TEV incluem idade avançada, imobilização prolongada, cirurgia, fraturas, uso de contraceptivos orais, gestação, puerpério, neoplasias e a síndrome antifosfolípide, e não serão aqui abordados. Neste capítulo, conceitos atualizados acerca da participação de fatores genéticos, determinando o risco de TEV, serão apresentados. Adicionalmente, a utilização de ferramentas de diagnóstico molecular em doenças multigênicas será exemplificada, tomando-se as trombofilias como protótipos de doença multigênica.

\section{TROMBOFILIAS: MANIFESTAÇÕES E RELEVÂNCIA CLÍNICA}

TEV é uma entidade clínica, cuja importância pode ser apreciada, analisando-se sua alta incidência em diversas populações: acomete cerca de 1/1000 indivíduos por ano, sendo responsável, nos Estados Unidos, por 50000 óbitos/ano. As apresentações clínicas usuais incluem a trombose venosa profunda (TVP) de membros inferiores e embolia pulmonar (EP), embora mais raramente o episódio trombótico possa ocorrer em outros sítios (veias retinianas, mesentéricas, de membros superiores, cerebrais, e tromboflebites superficiais de repetição). Pacientes com trombofilia de base genética exibem ainda predisposição aumentada para a ocorrência da TEV que tende a ser recorrente e acometer predominantemente indivíduos relativamente jovens, e em até $1 / 3$ dos casos uma história familiar para TEV pode ser detectada ${ }^{(2,3)}$.

\section{DEFICIÊNCIA DE ANTITROMBINA, PRO- TEÍNA $C$ E PROTEÍNA $S$ COMO FATORES DE RISCO GENÉTICOS PARA TROMBO- SE VENOSA}

Durante a ativação do sistema de coagulação do sangue, diversas serinoproteases com alta capacidade pró-coagulante são subseqüientemente produzidas, culminando na formação de um coágulo estável de fibrina. A atividade dessas proteases é regulada por um conjunto de proteínas genericamente conhecidas como anticoagulantes naturais ou inibidores fisiológicos da coagulação, cujos principais representantes são a antitrombina (AT), proteína C (PC) e proteína $S$ (PS).

A AT (anteriormente designada AT III) é o inibidor primário da trombina e também exerce efeito inibitório sobre diversas outras enzimas da coagulação, incluindo os fatores IXa, Xa, e XIa. Adicionalmente, a AT acelera a dissociação do complexo fator VIIa-fator tecidual e impede sua reassociação. Tendo em vista seu papel como inibidor fisiológico da coagulação, pode-se compreender por que alterações moleculares, que resultam em deficiência de AT, são causas de trombofilia. De fato, a deficiência de AT foi a primeira anormalidade genética, associada a trombose familiar: em 1965, Egeberg descreveu família norueguesa em que diversos indivíduos, apresentando deficiência de antitrombina (concentrações plasmáticas entre 40 e $50 \%$ do normal) apresentavam fenô- 
menos trombóticos. Desde então, numerosos estudos descreveram famílias, apresentando constelação similar de anormalidades clínicas e laboratoriais, consolidando o conceito de que a deficiência de AT é fator de risco genético para trombofilia ${ }^{(2)}$. O padrão de herança da deficiência familiar de AT é, usualmente, autossômico dominante, homens e mulheres sendo igualmente afetados. A deficiência heterozigótica de AT é associada a risco aumentado para TEV de aproximadamente 10 vezes. Não foi descrito, até o momento, homozigose para deficiência de AT e especula-se que a mesma possa ser incompatível com a vida. Nos últimos anos, a identificação de diferentes mutações em casos de deficiência de AT revelou que suas bases moleculares são altamente heterogêneas, uma miríade de defeitos moleculares tendo sido identificados até então. É interessante notar que, após a descrição inicial da associação de deficiência de AT com TEV, reforçou-se, na época, a noção de que trombofilia seria uma doença monogênica com penetrância incompleta, visão que, consoante exposto abaixo, foi substancialmente modificada nas décadas subsequientes.

As deficiências de PC e PS envolvem defeitos em uma das vias de anticoagulação do sangue: o sistema da PC ativada. A PC é ativada após a ligação da trombina ao receptor endotelial trombomodulina, e inibe a coagulação, clivando e inativando os fatores Va e VIIIa. Tais reações são potencializadas pela PS, que atua como um cofator não enzimático. Nesse contexto, pode-se prever que deficiências dos anticoagulantes naturais PC e PS são associadas a um estado de hipercoagulabilidade e a risco aumentado para TEV. De fato, na década de 1980, defeitos genéticos, resultando em deficiência de PC e PS foram reconhecidos, pela primeira vez, como causas de trombofilia familiar. Deficiências heterozigóticas de PC e PS são associadas a risco estimado para ocorrência de TEV aproximadamente 10 vezes maior em comparação a indivíduos normais. Homozigose para deficiência de PC ou PS é associada ao quadro clínico grave de purpura fulminans neonatal, caracterizado por trombose de microcirculação, que se manifesta logo após o nascimento. Assim, como no caso da deficiência de AT, as bases moleculares das deficiências de PC e PS foram desvendadas em diversas famílias, e exibem evidente diversidade genética.

A heterogeneidade de defeitos moleculares, subjacentes aos estados de deficiência de AT, PC e PS implicam em dificuldade óbvia na utilização de métodos moleculares, como rotina da investigação dos citados estados trombofílicos. De fato, as técnicas de análise gênica, que resultaram na elucidação das bases moleculares dos defeitos não são aplicadas como primeira linha de investigação em casos de trombofilia e é pouco provável que, mesmo no futuro, a procura de mutações nos genes dos três anticoagulantes naturais faça parte do armamentário diagnóstico de "screening" em pacientes com TEV. Dessa forma, o diagnóstico das deficiências de AT, PC e PS é estabelecido por meio da dosagem das respectivas proteínas no plasma, utilizando-se métodos funcionais ou imunológicos.

Finalmente, vale ressaltar que, embora as deficiências de AT, PC e PS sejam fatores de risco independentes para TEV, em conjunto, tais anormalidades respondem por apenas 5 a $15 \%$ do total de casos de TEV em diferentes populações até então estudadas (Tabela I). Portanto, essas deficiências, isoladamente, são causas bem estabelecidas, porém relativamente raras de trombofilia.

\section{RESISTÊNCIA À PROTEÍNA $C$ ATIVADA E MUTAÇÃO FV: ${ }^{506}$ (FATOR $V$ LEIDEN): PRINCIPAL ANORMALIDADE GENÉTICA ENVOLVIDA NA ETIOLOGIA DAS TROM- BOFILIAS}

Até recentemente, na maior parte dos casos de TEV, não era possível identificar um fator genético envolvido, já que as deficiências hereditárias de anticoagulantes naturais respondem por, no máximo, $15 \%$ dos casos de trombofilia. O panorama alterou-se significativamente em 1993, com a descrição por Dahlbäck e colegas do fenótipo conhecido como resistência à proteína $\mathrm{C}$ ativada (RPCA), como uma anormalidade altamente prevalente em pacientes com trombofilia hereditária ${ }^{(4,5)}$. Utilizando um ensaio de TTPA modificado, foi observado que a adição de PC ativada ao plasma de $40 \%$ pacientes com TEV não resultava no prolongamento esperado desse tempo de coagulação. A RPCA era uma anormalidade herdada na maior parte dos casos e uma associação com incidência aumentada de trombose foi também demonstrada nos familiares com fenótipo similar ${ }^{(6)}$. No mesmo ano, numerosos laboratórios utilizaram modificações do teste de RPCA e confirmaram a importância desse fenótipo anormal como um fator de risco para trombose venosa.

RPCA hereditária é, em ao menos 95\% dos casos, decorrente de uma mutação no fator $\mathrm{V}$ da coagulação: uma transição $\mathrm{G} \rightarrow \mathrm{A}$ na posição 1691 do gene, resultando na substituição de Arginina (R) por 
Glutamina (Q) na posição do amino ácido 506 (que constitui sítio de clivagem da PC ativada na molécula do fator $\mathrm{V})^{(4,5,6)}$. Tal mutação de ponto foi, pela primeira vez, descrita em 1994 e é, atualmente, conhecida como fator V Leiden (FVL), FVR ${ }^{506} \mathrm{Q}$, ou FV: $\mathrm{Q}^{506}$ $(4,5,6)$. $\mathrm{O}$ fator $\mathrm{V}$ mutante é resistente à neutralização mediada pela PC ativada, o que resulta no fenótipo de RPCA. FVL é, portanto, associado a um estado de hipercoagulabilidade e susceptibilidade aumentada para a ocorrência de TEV. FVL aumenta o risco para TEV em aproximadamente 3 a 8 vezes em heterozigose e em 50-100 vezes em homozigose. Em contraste com a raridade dos defeitos genéticos, associados a deficiência de AT, PC e PS, a mutação do FVL é altamente prevalente em diversas populações caucasianas até então investigadas (frequiências variando de 1 a 15\%), e é considerado o mais freqüente defeito genético, envolvido na etiologia das trombofilias, sendo encontrado em 10 a $60 \%$ dos casos de TEV (Tabela I). Recentemente, duas mutações no gene do fator $\mathrm{V}$, afetando outro sítio de clivagem da PC (fator V Cambridge, FV:R306T e fator V Hong-Kong, FV:R306G), foram descritas, mas não parecem ser fatores de risco para TEV ${ }^{(7)}$.

O diagnóstico de RPCA, atualmente realizado como rotina na investigação de TEV, pode ser estabelecido, utilizando-se o ensaio baseado no TTPA, e a mais recente utilização de plasma deficiente em fator $\mathrm{V}$ para diluição das amostras testadas resulta em discriminação confiável entre indivíduos não portadores, portadores heterozigotos e portadores homozigotos da mutação do FVL. Alternativamente, técnicas de análise gênica, baseadas em amplificação por PCR do exon 10 do fator $\mathrm{V}$ podem ser utilizadas para identificação precisa da mutação do FVL.

A identificação do FVL como anormalidade molecular, presente em grande parte dos casos de TEV resultou em alteração substancial da nossa visão acerca dessa entidade clínica, que deixou de ser compreendida como doença meramente adquirida. Em que se pese a importância de fatores adquiridos, há que se entender que TEV é, também, uma doença em que fatores genéticos contribuem significativamente para a ocorrência.

\section{MUTAÇÃO G20210A DO FATOR II DA COAGULAÇÃO}

Em 1996, um novo fator genético, envolvido na etiologia do TEV foi descrito: uma transição $\mathrm{G} \rightarrow \mathrm{A}$ no nucleotídeo 20210 na região não traduzida a 3' do gene do fator II da coagulação (FII, protrombina) ${ }^{(8)}$. FII G20210A é associado a hiperprotrombinemia, formação aumentada de trombina, e risco aumentado para ocorrência de TEV ${ }^{(2,8,9)}$. A mutação é encontrada em 1 a 3\% de indivíduos da população geral, e em 6 a $18 \%$ dos pacientes com TEV (Tabela I). Assim, FII G20210A pode ser considerada a segunda anormalidade genética mais freqüentemente associada às trombofilias, e sua descrição veio reforçar o conceito de que fatores genéticos determinam o risco de TEV. O diagnóstico da anormalidade, em geral, é estabelecido por técnicas de análise gênica, baseadas na amplificação do DNA genômico por PCR e reconhecimento da mutação por digestão enzimática.

\section{HIPER-HOMOCISTEINEMIA}

Hiper-homocisteinemia (elevação anormal das concentrações plasmáticas do amino ácido homocisteína) é um fator de risco estabelecido para TEV (Tabela I), e variáveis genéticas e ambientais interagem para determinar os níveis plasmáticos de homocisteína ${ }^{(10,11)}$. Causas adquiridas de hiper-homocisteinemia incluem deficiências nutricionais de vitamina B6, vitamina B12 ou folato, idade avançada, insuficiência renal crônica e uso de antifólicos. Defeitos genéticos, envolvendo as enzimas, metileno tetraidrofolato redutase (MTHFR) e cistationina $\beta$ - sintase(CBS), que participam do metabolismo intracelular da homocisteína, também podem resultar em deficiência enzimática e hiper-homocisteinemia. Numerosas mutações da MTHFR e CBS foram identificadas; a maior parte delas são raras e somente têm conseqüência clínica em homozigose, condição em que os pacientes apresentam quadro clínico complexo, caracterizado por déficits neurológicos variados, retardo psicomotor, convulsões, doença arterial prematura e TEV. Em contraste com a raridade desses defeitos, duas mutações da MTHFR $(677 \mathrm{C} \rightarrow$ T e $1298 \mathrm{~A} \rightarrow \mathrm{C}$ ) e uma mutação da CBS (844ins68) são prevalentes e merecem discussão adicional. MTHFR $677 \mathrm{C} \rightarrow \mathrm{T}$ (em homozigose) é associada a atividade enzimática reduzida, termolabilidade e hiper-homocisteinemia leve a moderada, mas seu papel, como fator de risco para TEV, é ainda controverso. MTHFR $1298 \mathrm{~A} \rightarrow \mathrm{C}$ isoladamente não parece ser associada a hiper-homocisteinemia, mas heterozigose combinada com MTHFR $677 \mathrm{C} \rightarrow \mathrm{T}$ é associada a diminuição de atividade enzimática e hiperhomocisteinemia. Embora MTHFR $1298 \mathrm{~A} \rightarrow$ C isoladamente não pareça influenciar o risco de $\mathrm{TEV}^{(12)}$, estudos adicionais são necessários para definir o seu 
papel, em especial em combinação com MTHFR 677 $\mathrm{C} \rightarrow \mathrm{T}$, determinando o risco de TEV. Uma inserção de 68-pb no gene da CBS (844ins68) é também uma mutação prevalente em diferentes populações, mas tal variação genética não parece afetar o risco de TEV ${ }^{(13)}$.

Hiper-homocisteinemia é usualmente diagnosticada por meio da dosagem plasmática de homocisteína basal e após sobrecarga com metionina (utilizando-se a técnica de cromatografia líquida por HPLC e detecção eletroquímica ou por fluorescência). Já que nenhuma alteração genética foi inequivocamente identificada como fator de risco para trombofilia, até o momento, a pesquisa sistemática de mutações da MTHFR e CBS não é usualmente efetuada como rotina na investigação de casos de TEV.

\section{NÍVEIS PLASMÁTICOS ELEVADOS DE FATORES DA COAGULAÇÃO}

Os níveis plasmáticos do fator VIII da coagulação, provavelmente, refletem a influência combinada de fatores genéticos e adquiridos. Por exemplo, genes que codificam os grupos sangüíneos $\mathrm{ABO}$ e o fator de von Willebrand influenciam os níveis de fator VIII no plasma. Adicionalmente, agregação familiar de níveis elevados de fator VIII (não associada a grupo sangüíneo ou FVW) foi também descrita, apontando para a existência de componentes genéticos, desconhecidos influindo nas concentrações plasmáticas do fator ${ }^{(2)}$. Concentrações plasmáticas de fator VIII acima de $1500 \mathrm{UI} / 1$ (150\% do normal) representam um fator de risco para trombofilia, visto que são encontradas em frequiência significativamente maior em pacientes com trombose venosa do que na população geral (Tabela I). Entretanto, nenhuma anormalidade molecular específica foi até então identificada no gene do fator VIII como fator de risco para TEV. Adicionalmente, a utilidade da determinação das concentrações plasmáticas de fator VIII, em pacientes com TEV, merece investigação adicional antes que seja instituída como prática de rotina.

Níveis plasmáticos elevados de fibrinogênio aparentemente são associados a risco aumentado para ocorrência de TEV (2). Todavia, estudos adicionais são necessários para definir a exata prevalência e o significado clínico dessa alteração no TEV, assim como a utilidade da deter- minação rotineira dos níveis plasmáticos de fibrinogênio dos pacientes.

Recentemente, foi descrita associação entre níveis elevados de fator XI e fator IX da coagulação e risco aumentado de TEV ${ }^{(3,14)}$.

\section{FATOR XIII VAL34LEU}

Em 1999, dois laboratórios descreveram a associação entre um polimorfismo no gene do fator XIII da coagulação e TEV ${ }^{(15,16)}$. Uma mutação (transição $\mathrm{G} \rightarrow \mathrm{T}$ no exon 2 do gene que codifica a subunidade $\mathrm{A}$ do fator XIII) resulta na substituição de Valina por Leucina na posição do aminoácido 34 (FXIII Val34Leu). Um significante efeito protetor para a ocorrência de TEV foi descrito, e, portanto, FXIII Val34Leu adiciona complexidade à lista de alterações genéticas que influenciam o risco de TEV, caso em que o fator genético, exerce um efeito antitrombótico (Tabela I). Vale ressaltar que o alelo mutante (Leu34) influencia a atividade de transglutaminase do fator XIII: a homozigose para à mutação é associada à atividade enzimática aumentada, e heterozigotos apresentam atividade de transglutaminase intermediária, em comparação a não portadores da mutação. Já que um aumento de atividade do fator XIII deveria ser associado a um coágulo de fibrina mais estável, o efeito protetor para TEV, conferido pela mutação, é inesperado e, portanto, os mecanismos pelos quais FXIII Val34Leu

\begin{tabular}{|c|c|c|}
\hline Fator de risco & População geral & Pacientes comTEV \\
\hline Deficiência de AT & $0,02 \%$ & $1-3 \%$ \\
\hline Deficiência de PC & $0,2-0,4 \%$ & $3-5 \%$ \\
\hline Deficiência de PS & $?$ & $1-5 \%$ \\
\hline Fator V Leiden & $1-15 \%$ & $10-60 \%$ \\
\hline FII G20210A & $2-5 \%$ & $6-18 \%$ \\
\hline Hiper-homocisteinemia & $5 \%$ & $10 \%$ \\
\hline Níveis elevados de FVIII & $11 \%$ & $25 \%$ \\
\hline Fator XIII Val34Lei & $10 \%$ & $1,6 \%$ \\
\hline \multicolumn{3}{|c|}{$\begin{array}{l}\text { Tabela adaptada da Ref. } 12 \\
\text { "Homozigose para a mutaçốo (Ref. 9) }\end{array}$} \\
\hline
\end{tabular}


exerce efeito antitrombótico são ainda desconhecidos. Adicionalmente, estudos prospectivos são necessários para confirmar o papel protetor, exercido por esta alteração genética nas doenças trombóticas, assim como para investigar seu potencial de determinar o risco de trombose em portadores de outras anormalidades genéticas, associadas à trombofilia.

\section{INTERAÇÃO DE FATORES DE RISCO DETERMINANDO O RISCO DE TEV}

Quando um fator de risco é reconhecido como tal, pode ser dito que ele aumenta o risco de trombose em certa extensão, ou que ele aumenta a probabilidade de ocorrência da doença em indivíduos expostos ao fator, em comparação a indivíduos não expostos. Portanto, em princípio, as probabilidades de ocorrência de TEV são maiores naqueles com o fator de risco do que naqueles sem o fator. Todavia, alguns indivíduos, que são expostos a fatores de risco não apresentam trombose, ao passo que outros não expostos podem desenvolver a doença. Pode ser especulado que diferenças entre os eventos reais e as probabilidades esperadas são o resultado de interações: entre aqueles indivíduos com um risco geral para apresentar TEV, há subgrupos com risco maior e subgrupos com risco menor. Os fatores que discriminam entre os subgrupos são os fatores que levam à interação, fenômeno também conhecido como sinergismo ou modificação de efeito ${ }^{(2)}$.

Sabe-se que herança combinada de fatores genéticos, associados à trombofilia, resulta em amplificação do risco para a ocorrência do episódio trombótico. Por exemplo, indivíduos com deficiência de PC, que também são portadores da mutação do FVL, apresentam risco aumentado para TEV em comparação a indivíduos com deficiência de PC sem a mutação do $\mathrm{FVL}^{(2)}$. Achados similares foram descritos em famílias com deficiência de AT, deficiência de PS e com FII G20210A: a herança combinada de um desses defeitos com o FVL resulta em risco aumentado para $\mathrm{TEV}^{(2)}$. Em conjunto, tais dados constituem exemplos de interação entre fatores genéticos, determinando o risco de TEV. Adicionalmente, esses achados sugerem que a heterogeneidade de manifestações clínicas (isto é, ocorrência de trombose) em indivíduos na mesma família e em diferentes famílias pode ser explicada pela presença ou ausência de defeitos genéticos adicionais ${ }^{(2)}$.

Interação entre fatores de risco genéticos e adquiridos para trombose também ocorre, quando dois fatores de risco, presentes em combinação, resultam em efeito que exceda a soma de seus efeitos (esperados) quando presentes isoladamente. A combinação de deficiência de AT, PC, PS, FVL e FII G20210A com fatores adquiridos para TEV, como gestação, puerpério, uso de anticoncepcional oral (ACO), por exemplo, pode resultar em efeito interativo e portanto em risco amplificado para a ocorrência de trombo$\mathrm{se}^{(2)}$. Esse conceito pode ser exemplificado, analisando-se especificamente a presença de interação entre o FVL e o uso de ACO (Tabela II): o risco de TEV em mulheres em uso de ACO, que são portadoras do FVL excede a soma dos efeitos separados dos dois fatores de risco.

A Tabela III apresenta lista de fatores de risco, estabelecidos para TEV. Embora a maior parte dos fatores de risco possam ser classificados em hereditários e adquiridos, alguns (hiper-homocisteinemia, níveis de fator VIII) resultam da influência combinada de variáveis genéticas e ambientais. O conhecimento de que esses fatores podem interagir dinamicamente para determinar o risco de TEV pode ser útil para a compreensão da patogênese da doença.

\section{INVESTIGAÇÃO DIAGNÓSTICA DE FA- TORES DE RISCO GENÉTICOS PARA TROMBOFILIA}

$\mathrm{Na}$ Tabela IV, encontram-se apresentados os métodos diagnósticos primários e secundários, utilizados na investigação etiológica das trombofilias. O dia- 


\begin{tabular}{|lll|}
\hline \multicolumn{2}{|l}{ Tabela III: Fatores de risco para TEV. } \\
\hline Hereditários & Adquincios & Mistos \\
\hline Deficiência de AT & Idade & Hiper-homocisteinemia \\
Deficiência de PC & Imobilizaçẫo & $\uparrow$ niveis de fator VIII \\
Deficiência de PS & Operaçỗes & $\uparrow$ niveis de fibrinogênio \\
F ator V Leiden & Neoplasias & $\uparrow$ níveis de fator XI \\
FII G20210A & Anticoncepcional oral & $\uparrow$ níveis de fator IX \\
& Reposiçẫo hormonal & \\
& Síndrome antifosfolípide & \\
& Doenças \\
& mieloproliferativas \\
\hline
\end{tabular}

nenhuma alteração genética associada a hiper-homocisteinemia foi inequivocamente identificada como fator de risco para trombofilia, até o momento, a pesquisa sistemática de mutações da MTHFR e CBS não é usualmente efetuada como rotina na investigação de casos de TEV.

$\mathrm{Na}$ maior parte dos centros, recomenda-se a utilização desse painel de investigação como rotina para indivíduos relativamente jovens ( $<50-55$ anos) com diagnóstico objetivo de TEV e sem diagnóstico concomitante de neoplasia. Entretanto, os critérios de investigação devem ser definidos em cada centro e, evengnóstico das deficiências de AT, PC e PS é estabelecido por meio da dosagem das respectivas proteínas no plasma, utilizando-se métodos funcionais ou imunológicos. O diagnóstico de RPCA pode ser estabelecido, utilizando-se o ensaio baseado no TTPA (vide supra), sendo que o emprego de plasma deficiente em fator V para diluição das amostras testadas resulta em discriminação precisa entre heterozigotos, homozigotos e não portadores do FVL. Alternativamente, técnicas de análise gênica, baseadas em amplificação por PCR do exon 10 do fator $\mathrm{V}$ podem ser utilizadas para identificação precisa da mutação do FVL. O diagnóstico da mutação FII G20210A deve ser estabelecido por técnicas de análise gênica, baseadas na amplificação do DNA genômico por PCR, seguida, usualmente, de reconhecimento da mutação por digestão enzimática. Embora haja uma associação entre FII G20210A e hiperprotrombinemia, a simples determinação dos níveis plasmáticos de protrombina não confirma ou afasta a presença da mutação, e, portanto, a análise molecular é a única ferramenta diagnóstica disponível para diagnóstico preciso do FII G20210A. Hiper-homocisteinemia é diagnosticada por meio da dosagem plasmática de homocisteína basal, utilizando-se a técnica de cromatografia líquida por HPLC e detecção eletroquímica ou por fluorescência. Em alguns centros, além da dosagem basal de homocisteína, é realizada nova dosagem após teste de sobrecarga oral com metionina. Já que tualmente, podem sofrer variações dependentes de análise individual de casos. A extensão da investigação a familiares, embora possa resultar na identificação de portadores assintomáticos (informação potencialmente relevante para profilaxia de eventos trombóticos, quando da exposição a fatores de risco circunstanciais ou para recomendação de não exposição a alguns desses fatores) ainda é tema controverso e não é realizada rotineiramente em numerosos centros. Portanto, é fundamental compreender que a dificuldade não é relativa somente à realização dos testes, mas, em especial, à definição precisa dos reais benefícios referentes à prevenção e terapêutica do TEV após a identificação de portadores assintomáticos.

\begin{tabular}{|c|c|c|}
\hline Fator de risco & Método primário & Método secundário \\
\hline Deficiência de AT & Dosagem plasmática* & Análise gênica \\
\hline Deficiência de PC & Dosagem plasmática* & Análise gênica \\
\hline Deficiência de PS & Dosagem plasmática* & Análise gênica \\
\hline \multirow[t]{2}{*}{ RPCANFVL } & Teste de RPCA & -------- \\
\hline & Análise gênica & \\
\hline F\| G20210A & Análise gênica & --1-- \\
\hline Hiper-homocisteinemia & Dosagem plasmática & Análise gênica" \\
\hline \multicolumn{3}{|c|}{$\begin{array}{l}\text { * Método funcional para dosacem de AT e PC e método imunolóqico para } \\
\text { dosaqem de PS. Métodos imunolóqicos podem ser utilizados para } \\
\text { Caracterizaç̃o adicional de casos de deficiência de AT e PC } \\
\text { " Nenhuma mutaç̃o foi inequivocamente associada a risco aumentado para TEV }\end{array}$} \\
\hline
\end{tabular}




\section{PROFILAXIA DO TEV NAS TROMBOFI- LIAS HEREDITÁRIAS}

Profilaxia anticoagulante pode ser recomendada em diversas situações, em portadores de alterações genéticas, ligadas a trombofilia. Neste sentido, vale ressaltar que informações confiáveis acerca do risco de trombose em portadores de diferentes anormalidades seriam necessárias para que decisões mais acertadas quanto à profilaxia fossem tomadas, com base no balanço entre os riscos e benefícios do procedimento. Infelizmente, há escassez de dados que guiem esse tipo de conduta e, de fato,, o manejo do paciente trombofílico deve incluir avaliação individualizada do risco de TEV em cada caso. As sugestões para profilaxia, apresentadas nas Tabelas V e VI incluem as utilizadas por este autor em seu serviço, foram formuladas com base nas informações disponíveis até o

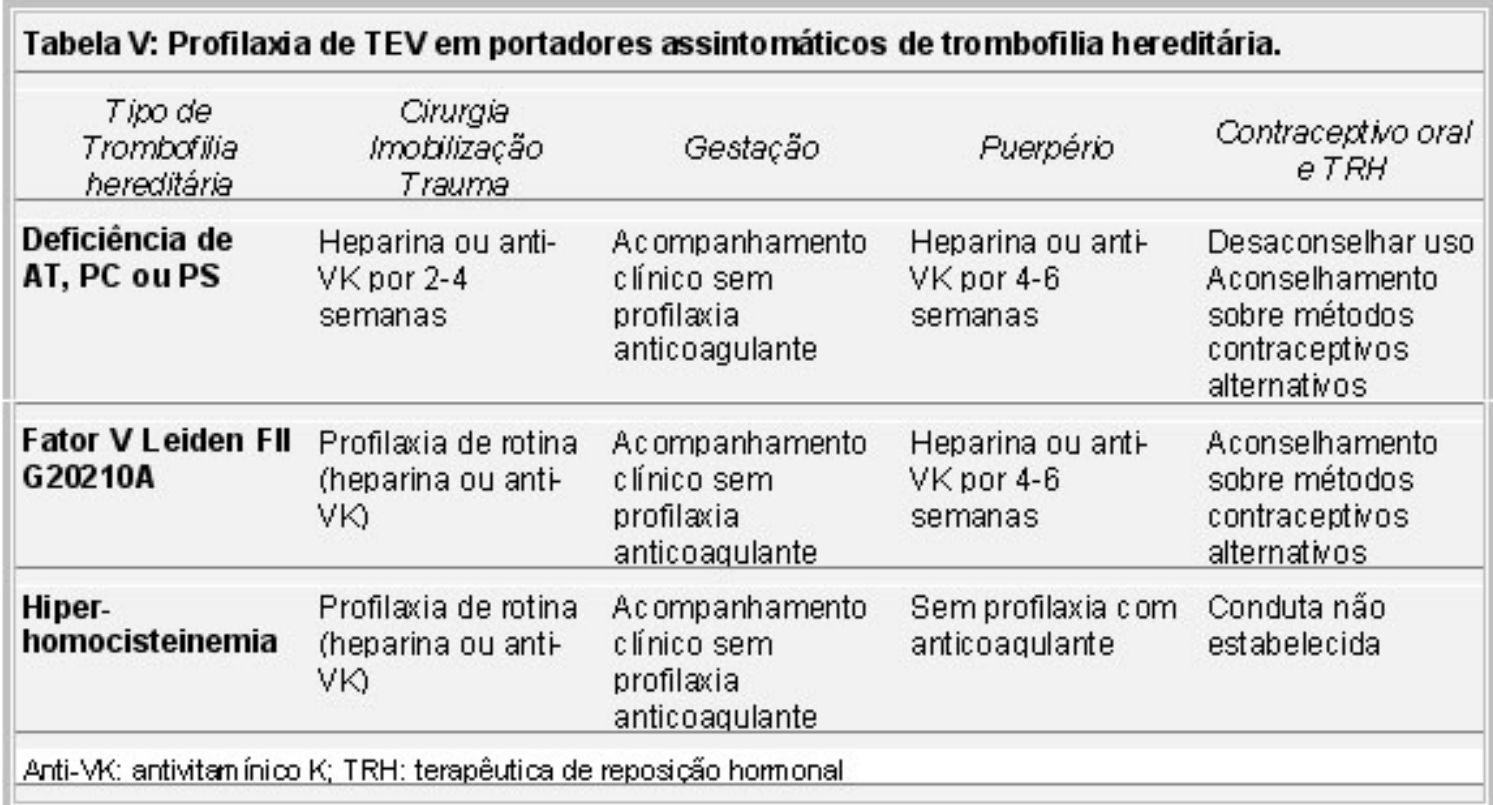

\begin{tabular}{|c|c|c|c|c|}
\hline $\begin{array}{l}\text { Tipo de } \\
\text { Trombofilia } \\
\text { hereditaria }\end{array}$ & $\begin{array}{l}\text { Cirurgia } \\
\text { imobilização } \\
\text { Trauma }\end{array}$ & Gestação & Puerpério & $\begin{array}{c}\text { Contraceptivo } \\
\text { orale TRH }\end{array}$ \\
\hline $\begin{array}{l}\text { Deficiência de } \\
\text { AT, PC ou PS }\end{array}$ & $\begin{array}{l}\text { Heparina ou anti- } \\
\text { VK por } 2-4 \\
\text { semanas }\end{array}$ & $\begin{array}{l}\text { Profilaxia com } \\
\text { heparina durante } \\
\text { toda a qestacão* }\end{array}$ & $\begin{array}{l}\text { Heparina ou anti } \\
\text { VK por } 4-6 \\
\text { semanas }\end{array}$ & $\begin{array}{l}\text { Desaconselhar uso } \\
\text { Aconselhamento } \\
\text { sobre outros } \\
\text { métodos } \\
\text { contraceptivos }\end{array}$ \\
\hline $\begin{array}{l}\text { Fator V Leiden FII } \\
\text { G20210A }\end{array}$ & $\begin{array}{l}\text { Profilaxia de rotina } \\
\text { (heparina ou anti- } \\
\text { VKo: considerar } \\
\text { profilaxia por } 4 \\
\text { semanas }\end{array}$ & $\begin{array}{l}\text { Profilaxia com } \\
\text { heparina durante } \\
\text { toda a qestacão* }\end{array}$ & $\begin{array}{l}\text { Heparina ou anti- } \\
\text { VK por } 4-6 \\
\text { semanas }\end{array}$ & $\begin{array}{l}\text { Desaconselhar uso } \\
\text { Aconselhamento } \\
\text { sobre outros } \\
\text { métodos } \\
\text { contraceptivos }\end{array}$ \\
\hline $\begin{array}{l}\text { Hiper- } \\
\text { homocisteinemia }\end{array}$ & $\begin{array}{l}\text { Profilaxia de rotina } \\
\text { (heparina ou anti- } \\
\text { VK }\end{array}$ & $\begin{array}{l}\text { Conduta nẫo } \\
\text { estabelecida }\end{array}$ & $\begin{array}{l}\text { Conduta nẫo } \\
\text { estabelecida }\end{array}$ & $\begin{array}{l}\text { Desaconselhar uso } \\
\text { Aconselhamento } \\
\text { sobre outros } \\
\text { métodos } \\
\text { contraceptivos }\end{array}$ \\
\hline
\end{tabular}


momento acerca do risco de TEV em pacientes com trombofilias hereditárias em diferentes situações e podem ser alteradas no futuro, a depender da disponibilidade de novos dados sobre o tema.

\section{TRATAMENTO DO TEV NAS TROM- BOFILIAS HEREDITÁRIAS}

O tratamento do episódio agudo de TEV em pacientes com trombofilias hereditárias não difere do tratamento recomendado para os quadros de TEV em pacientes sem anormalidades trombofílicas hereditárias. Após o diagnóstico objetivo do episódio trombótico (ultra-sonografia ou venografia nos casos de trombose venosa profunda, e cintilografia de ventilação/perfusão nos casos de embolia pulmonar), terapêutica com heparina deve ser instituída e mantida por, pelo menos, cinco dias, e o anticoagulante oral (antivitamínico-K) deve ser iniciado nas primeiras 24 horas, de modo a atingir um valor de INR na faixa de 2,0 a 3,0. A duração ideal da anticoagulação oral, em pacientes com trombofilia hereditária, não é conhecida e os dados apresentados na Tabela VII derivam principalmente de dados obtidos com pacientes sem trombofilia hereditária.

Pacientes com deficiência de AT, em geral, respondem à heparinização. Quando necessário, doses maiores de heparina podem ser administradas para atingir o prolongamento desejado do TTPA. Não há evidência de que o uso de concentrados de AT resulte em maior eficácia em tais casos. Em raros casos de deficiência de PC e PS, ocorre quadro de necrose cutânea associada ao uso de cumarínicos. Por essa razão, pacientes com diagnóstico de tais deficiências estabelecido na vigência de evento trombótico, somente devem receber o anticoagulante oral após a constatação da eficácia da heparinização.

\section{CONCLUSÕES}

Trombofilia é definida como uma predisposição aumentada, usualmente genética, para a ocorrência de TEV. Há evidência crescente de que numerosas anormalidades hereditárias, especialmente do sistema de coagulação e anticoagulação do sangue, são estreitamente associadas a trombofilia. Em conjunto, esses dados modificaram substancialmente o conceito de TEV que passou a ser compreendida como uma doença multigênica, na qual múltiplos fatores genéticos podem determinar o risco de trombose, e uma doença multifatorial, visto que fatores de risco genéticos interagem dinamicamente com fatores adquiridos, contribuindo para a ocorrência do evento trombótico ${ }^{(2,17,18,19)}$. A interação entre os diversos fatores de risco para trombofilia constitui campo de especial relevância, e investigações futuras são necessárias para a melhor compreensão do seu efeito, determinando o risco de TEV. Finalmente, as alterações conceituais acerca do TEV, aqui apresentadas, provavelmente resultarão, em

\begin{tabular}{|c|c|c|}
\hline \multicolumn{3}{|c|}{ Deficiências de AT, PC, PS, fator V Leiden, FII G20210A } \\
\hline Risco & Tratamento & \\
\hline Baixo (desencadeado por fator de risco reversivel) & $\begin{array}{l}\text { Heparina } 5-10 \text { dias } \\
\text { AntivK } 6 \text { meses }\end{array}$ & \\
\hline Intermediário (TEV espontâneo) & $\begin{array}{l}\text { Heparina } 5-10 \text { dias } \\
\text { AntiVK 6-12 meses }\end{array}$ & \\
\hline $\begin{array}{l}\text { Alto (recorrência, neoplasia, defeitos em homoziqose, combinacẫo de } \\
\text { defeitos hereditários) }\end{array}$ & $\begin{array}{l}\text { Heparina } 5-10 \text { dias } \\
\text { AntivK perene }\end{array}$ & \\
\hline \multicolumn{3}{|l|}{ Hiper-homocisteinemia } \\
\hline Primeiro episódio & $\begin{array}{l}\text { Heparina } 5-10 \text { dias } \\
\text { AntivK } 6 \text { meses } \\
\text { Suplementação vitamínica" }\end{array}$ & \\
\hline Recorrência & $\begin{array}{l}\text { Heparina } 5-10 \text { dias } \\
\text { AntivK } 12 \quad \text { meses } \\
\text { indefinidamente } \\
\text { Suplementaçấo vitamínica" }\end{array}$ & a \\
\hline \multicolumn{3}{|c|}{ 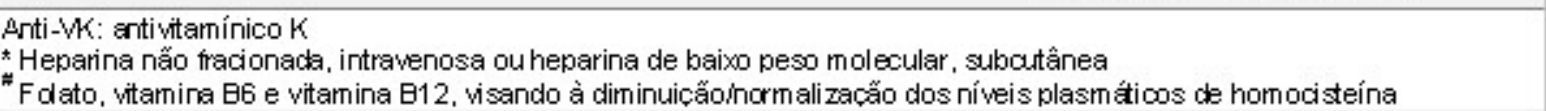 } \\
\hline
\end{tabular}


futuro próximo, em abordagem diagnóstica detalhada de casos da doença, com vistas à avaliação de risco individualizada. Tal avaliação diagnóstica poderá, ainda, fornecer a base para a definição de critérios prognósticos e estratégias terapêuticas, individualizadas, em pacientes com TEV ${ }^{(17,18)}$.

FRANCO RF. Inherited thrombophilias. Medicina, Ribeirão Preto, 34: 248-257, july/dec. 2001.

ABSTRACT: In this review we discuss the contribution of genetic factors to the occurrence of venous thromboembolism.

UNITERMS: Thrombosis. Gene. Risk Factors.

\section{REFERÊNCIAS BIBLIOGRÁFICAS}

1 - JORDAN FLJ \& NANDORFF A. The familial tendency in thromboembolic disease. Acta Med Scand 156: 267-275, 1956.

2 - ROSENDAAL FR. Venous thrombosis: a multicausal disease. Lancet 353: 1167-1173, 1999.

3 - VAN HYLCKAMA VLIEG A; VAN DER LINDEN IK; BERTINA RM \& ROSENDAAL FR. High levels of factor IX increase the risk of venous thrombosis. Blood 96: 3678-3682, 2000.

4 - SELIGSOHN U \& ZIVELIN A. Thrombophilia as a multigenic disorder. Thromb Haemost 78: 297-301, 1997.

5 - ZÖLLER B; GARCIA DE FRUTOS P; HILLARP A \& DAHLBÄCK $B$. Thrombophilia as a multigenic disease. Haematologica 84: 59-70, 1999.

6 - BERTINA RM; KOELEMAN RPC; KOSTER T; ROSENDAAL FR; DIRVEN RJ; DE RONDE H; VAN DER VELDEN PA \& REITSMA $\mathrm{PH}$. Mutation in blood coagulation factor $\mathrm{V}$ associated with resistance to activated protein C. Nature 369: 64-67, 1994.

7 - FRANCO RF; MAFFEI FH; LOURENÇO D; MORELLI V; THOMAZINI IA; PICCINATO CE \& ZAGO MA. Factor $V$ Arg306 $\rightarrow$ Thr (factor V Cambridge) and factor V Arg306®Gly mutations in venous thrombotic disease. $\mathrm{Br} \mathrm{J}$ Haematol 103: 888-890, 1998.

8 - POORT SW; ROSENDAAL FR; REITSMA PH \& BERTINA RM. A common genetic variation in the 3 '- untranslated region of the prothrombin gene is associated with elevated plasma prothrombin levels and an increase in venous thrombosis. Blood 88: 3698-3703, 1996.

9 - FRANCO RF; TRIP MD; TEN CATE H; VAN DEN ENDE A; PRINS $\mathrm{MH}$; KASTELEIN JJ \& REITSMA PH. The $20210 \mathrm{G} \rightarrow$ A mutation in the $3^{\prime}$ - untranslated region of the prothrombin gene and the risk for arterial thrombotic disease. $\mathrm{Br} \mathrm{J}$ Haematol 104: 5054, 1999.

10 - CATTANEO M. Hyperhomocysteinemia, atherosclerosis and thrombosis. Thromb Haemost 81: 165-176, 1999.
11- D' ANGELO A \& SELHUB J. Homocysteine and thrombotic disease. Blood 90: 1-11, 1997.

12 - FRANCO RF; MORELLI V; LOURENÇO D; MAFFEI FH; TAVELLA MH; PICCINATO CE; THOMAZINI IA \& ZAGO MA. A second mutation in the methylenetetrahydrofolate reductase gene and the risk of venous thrombotic disease. $\mathbf{B r} \mathbf{~ J}$ Haematol 105: 556-559, 1999.

13 - FRANCO R; MAFFEI F; LOURENÇO D; PICCINATO C; MORELLI V; THOMAZINI I \& ZAGO M. The frequency of 844ins68 mutation in the cystathionine $\beta$-synthase gene is not increased in patients with venous thrombosis. Haematologica 83:1006-1008, 1998.

14 - MEIJERS DC; TEKELENBURG WL; BOUMA BN; BERTINA RM \& ROSENDAAL FR. High levels of coagulation factor XI as a risk factor for venous thrombosis. N Engl J Med 342: 696701, 2000.

15 - CATTO AJ; KOHLER HP; COORE J; MANSFIELD MW; STICKLAND MH \& GRANT PJ. Association of a common polymorphism in the factor XIII gene with venous thrombosis. Blood 93: 906-908, 1999.

16 - FRANCO RF; REITSMA PH; LOURENÇO D; MAFFEI FH; MORELLI V; TAVELLA MH; ARAÚJO AG; PICCINATO CE \& ZAGO MA. Factor XIII Val34Leu is a genetic factor involved in the aetiology of venous thrombosis. Thromb Haemost 81: 676-679, 1999.

17 - FRANCO RF \& REITSMA PH. Genetic risk factors for venous thrombosis. Hum Genet 109:369-384, 2001.

18 - FRANCO RF \& ZAGO MA. The role of genetic factors in venous thrombosis. Ciênc Cult 52: 35-357, 2000.

19 - FRANCO RF \& REITSMA PH. Gene polymorphisms of the haemostatic system and the risk of arterial thrombotic disease. $\mathrm{Br}$ J Haematol 115: 491-506, 2001.

Recebido para publicação em 28/06/2001

Aprovado para publicação em 24/08/2001 